\title{
MicroRNAs as crucial mediators in the pharmacological activities of triptolide (Review)
}

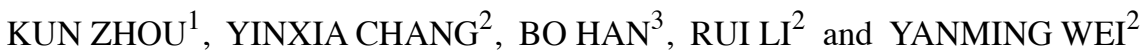 \\ ${ }^{1}$ Shanxi Institute of Energy, Taiyuan, Shanxi 030600; Colleges of ${ }^{2}$ Chinese Medicine and Food Engineering \\ and ${ }^{3}$ Basic Medicine, Shanxi University of Chinese Medicine, Jinzhong, Shanxi 030619, P.R. China
}

Received October 6, 2020; Accepted February 18, 2021

DOI: $10.3892 /$ etm.2021.9930

\begin{abstract}
Triptolide is the main bioactive constituent isolated from the Chinese herb Tripterygium wilfordii Hook F., which possesses a variety of pharmacological properties. MicroRNAs (miRNAs/miRs) are short non-coding RNAs that regulate gene expression post-transcriptionally. miRNAs are implicated in several intracellular processes, whereby their dysregulation contributes to pathogenesis of various diseases. Thus, miRNAs have great potential as biomarkers and therapeutic targets for diseases, and are implicated in drug treatment. Previous studies have reported that specific miRNAs are targeted, and their expression levels can be altered following exposure to triptolide. Thus, miRNAs are emerging as crucial mediators in the pharmacological activities of triptolide. The present review summarizes current literature on miRNAs as target molecules in the pharmacological activities of triptolide, including antitumor, anti-inflammatory, immunosuppressive, renal protective, cardioprotective, antiangiogenesis activities and multiorgan toxicity effects. In addition, the diverse signaling
\end{abstract}

Correspondence to: Dr Yanming Wei, College of Chinese Medicine and Food Engineering, Shanxi University of Chinese Medicine, No. 121, DaXue Street, Jinzhong, Shanxi 030619, P.R. China

E-mail: weiyanming2005@aliyun.com

Abbreviations: Hsp70, heat shock protein 70; VEGF, vascular endothelial growth factor; AKT, protein kinase B; AGO, argonaute protein; Mcl-1, myeloid cell leukemia-1; NF- $\mathrm{BB}$, nuclear factor kappa-B; PI3K, phosphatidylinositol 3 kinase; ERK, extracellular regulated protein kinase; mTOR, mammalian target of rapamycin; Cav-1, caveolin-1; PTEN, phosphatase and tensin homolog; MAPK, mitogen-activated protein kinase; TLR, Toll-like receptor; LPS, lipopolysaccharide; SHIP-1, Src homology 2-containing inositol phosphatase-1; SCI, spinal cord injury; SLE, systemic lupus erythematosus; TGF- $\beta$, transforming growth factor- $\beta$; DKD, diabetic kidney disease; Treg, regulatory T cells; ITGA5, integrin subunit $\alpha$ 5; AhR, aryl hydrocarbon receptor; EZH2, enhancer of zeste homolog 2

Key words: triptolide, microRNAs, antitumor, anti-inflammatory, immunosuppressive, renal protective, cardioprotective, antiangiogenesis, multiorgan toxicity pathways involved are discussed to provide a comprehensive understanding of the underlying molecular mechanisms of triptolide in the regulation of target miRNAs.

\section{Contents}

1. Introduction

2. An overview of miRNAs

3. Triptolide modulates the expression of miRNAs

4. Molecular mechanisms underlying regulation of miRNAs by triptolide

5. Conclusions and future perspective

\section{Introduction}

Traditional Chinese medicine is attracting great interest due to the high efficacy of its biological components for the treatment of several diseases. For example, Astragalus membranaceus is commonly used in various herbal formulations to cure inflammatory diseases and cancers (1), and Forsythia suspense-based treatments have provided notable protection against bacterial infections, allergies, neurodegeneration and cancers (2). Triptolide, a diterpenoid triepoxide, is one of the main active ingredients extracted from the traditional Chinese herb, Tripterygium wilfordii Hook F., which possesses several pharmacological activities. In preclinical in vitro and in vivo models, triptolide has exhibited a broad spectrum of potent antitumor activity $(3,4)$. Triptolide can induce cell cycle arrest, interfere with tumor cell proliferation, suppress cell migration, invasion and metastasis, prevent angiogenesis, enhance caspase-dependent and -independent cell death, and produce a synergistic effect in combination with antitumor drugs $(3,5)$. In addition, triptolide significantly inhibits the expression of pro-inflammatory cytokines and chemokines, and is considered a promising anti-inflammatory agent for the treatment of diseases, including rheumatoid arthritis (6). Triptolide exhibits profound immunosuppressive activity by regulating the proportion of immune cells and inhibiting the release of immune factors (7). Triptolide also alleviates renal and myocardial pathological injuries, and exerts protective roles in kidney and cardiovascular diseases $(8,9)$. However, despite its desirable clinical applications, treatment with triptolide is 
restricted due to its potential multiorgan toxicity, including hepatic, cardiac and reproductive toxicity (10).

Currently, the molecular mechanisms underlying the pharmacological activities of triptolide have been extensively investigated $(11,12)$, which have revealed various cellular targets and the involvement of different signaling pathways, including the heat shock protein 70 (Hsp70), vascular endothelial growth factor (VEGF), c-Jun and protein kinase B (AKT) pathways (13). MicroRNAs (miRNAs/miRs) are highly conserved endogenous small non-coding RNA molecules that negatively regulate gene expression. The phylogenetic conservation of several miRNAs across mammals highlights the importance of the miRNAs regulatory network (14). Consistently, extensive studies of miRNA knockout and overexpression models have suggested that miRNAs participate in various essential cellular processes, including cell differentiation, organ development, metabolism and apoptosis $(15,16)$. In addition, several diseases are associated with aberrant expression of miRNAs, and miRNAs exhibit potential as biomarkers and therapeutic targets for diseases, and are highly implicated in drug treatment (17). Increasing evidence suggest that miRNAs also serve as key regulatory elements for triptolide-mediated activity (18-22). Some studies assessing the effect of triptolide on miRNAs have demonstrated that the expression levels of specific miRNAs change several folds in different cell lines and tissues (23-25).

The present review summarizes miRNAs targeted by triptolide and discusses the underlying molecular mechanisms defining the association between the expression of miRNAs and triptolide to outline the critical roles these miRNAs play in the pharmacological activities of triptolide.

\section{An overview of miRNAs}

miRNAs are single-stranded RNA molecules that are 22 nucleotides in length, and their genes mostly reside in either introns or exons of non-coding transcripts, while others are located within introns of neighboring protein-coding pre-mRNAs and dispersed across the genome (26). miRNA genes are transcribed in the nucleus by RNA polymerase II or III into long primary transcripts called pri-miRNA, which are folded into double-stranded RNA hairpin. The pri-miRNA is cleaved by a microprocessor to release the miRNA precursor named pre-miRNA, containing a stem-loop of $\sim 60$ nucleotides, which is subsequently exported to the cytoplasm by exportin 5 and Ran-GTP $(15,27)$. In the cytoplasm, the pre-miRNA is further processed by the endonuclease, Dicer, to generate the small double-stranded miRNA duplex (28). Once formed, the miRNA duplex recruits argonaute protein (AGO) for unwinding (29). A strand of the duplex, namely mature miRNA, associates with the RNA induced silencing complex and mediates mRNA degradation or translational repression by binding to the partially complementary sequences of the 3'-untranslated region of specific mRNAs (30).

Similar to protein-coding genes, miRNAs are subjected to stringent regulation, and transcriptional regulation is a major contributor to the tissue- or development-specific gene expression of miRNAs (31). Furthermore, during the maturation steps, specific RNA binding proteins intricately interact with the processing machineries of a range of miRNAs through functional interactions, which subsequently modulates the expression of their target mRNAs (32). In addition, single nucleotide polymorphisms, RNA editing and methylation are considered important mechanisms that control the expression levels and functions of miRNAs (33).

\section{Triptolide modulates the expression of miRNAs}

Recent studies have demonstrated that miRNAs are involved in antitumor, anti-inflammatory and immunosuppressive activities of triptolide $(18,20,21,34-37)$. In addition, triptolide exerts renal protective, cardioprotective and antiangiogenesis functions by regulating the expression of miRNAs (38-42). Furthermore, miRNAs are closely associated with the multiorgan toxicity of triptolide $(23,43)$. Tables I and II list evidence supporting miRNAs as pivotal mediators in the pharmacological properties of triptolide.

miRNAs involved in the antitumor activity of triptolide. Several miRNAs act as tumor-suppressor genes or oncogenes, and increasing evidence suggest that the suppressive function of triptolide on multiple tumors is mediated by regulating miRNAs $(44,45)$. In human T-cell lymphocytic leukemia cells, triptolide significantly increases miR-16-1 expression and decreases miR-138-2 expression, and downregulation of miR-16-1 expression contributes to triptolide-induced apoptosis (46). Triptolide-induced hepatocellular carcinoma cell death is associated with the suppression of two oncogenic miRNA clusters, miR-17-92 and miR-106b-25 (24). In pancreatic cancer cells, treatment with triptolide increases miR-204 expression, which directly binds to myeloid cell leukemia-1 (Mcl-1), an antiapoptotic gene essential for cell survival (47), thereby inhibiting Mcl-1 protein expression and inducing cell-type dependent apoptosis or autophagic cell death (48). In addition, triptolide decreases miR-142-3p expression, which negatively regulates Hsp70 expression, a stress protein recognized as an apoptosis inhibitor (49), and suppresses pancreatic cancer cell proliferation (50). In vivo studies have confirmed that triptolide abrogates human pancreatic tumors xenografts by concurrent upregulation of miR-204 and miR-142-3p expression and downregulation of Mcl-1 or Hsp70 expression, respectively $(48,50)$. In colon carcinoma cells, treatment with triptolide downregulates miR-191 expression, which in turn suppresses cell proliferation and migration, induces apoptosis and activates the nuclear factor kappa-B (NF- $\kappa \mathrm{B})$ and $\mathrm{Wnt} / \beta$-catenin signaling pathways (34). Notably, these effects were reversed following transfection with miR-191 mimics, suggesting that the anti-colorectal cancer activities of triptolide are associated with the downregulation of miR-191 expression (34). Through upregulation of miR-146a expression, triptolide markedly decreases the expression levels of the RhoA and Racl genes in breast cancer cells, which are both key members of the Rho GTPase family involved in tumor invasion and metastasis, and thus act as metastasis suppressors (18). Triptolide also induces $\mathrm{S}$ phase cell cycle arrest of human nasopharyngeal carcinoma cells by enhancing p $85 \alpha$-phosphatase and tensin homolog (PTEN) complex formation and inactivating AKT-mediated cyclin-dependent kinase 2 phosphorylation, which requires downregulation of miR-144 expression (35). Triptolide also 


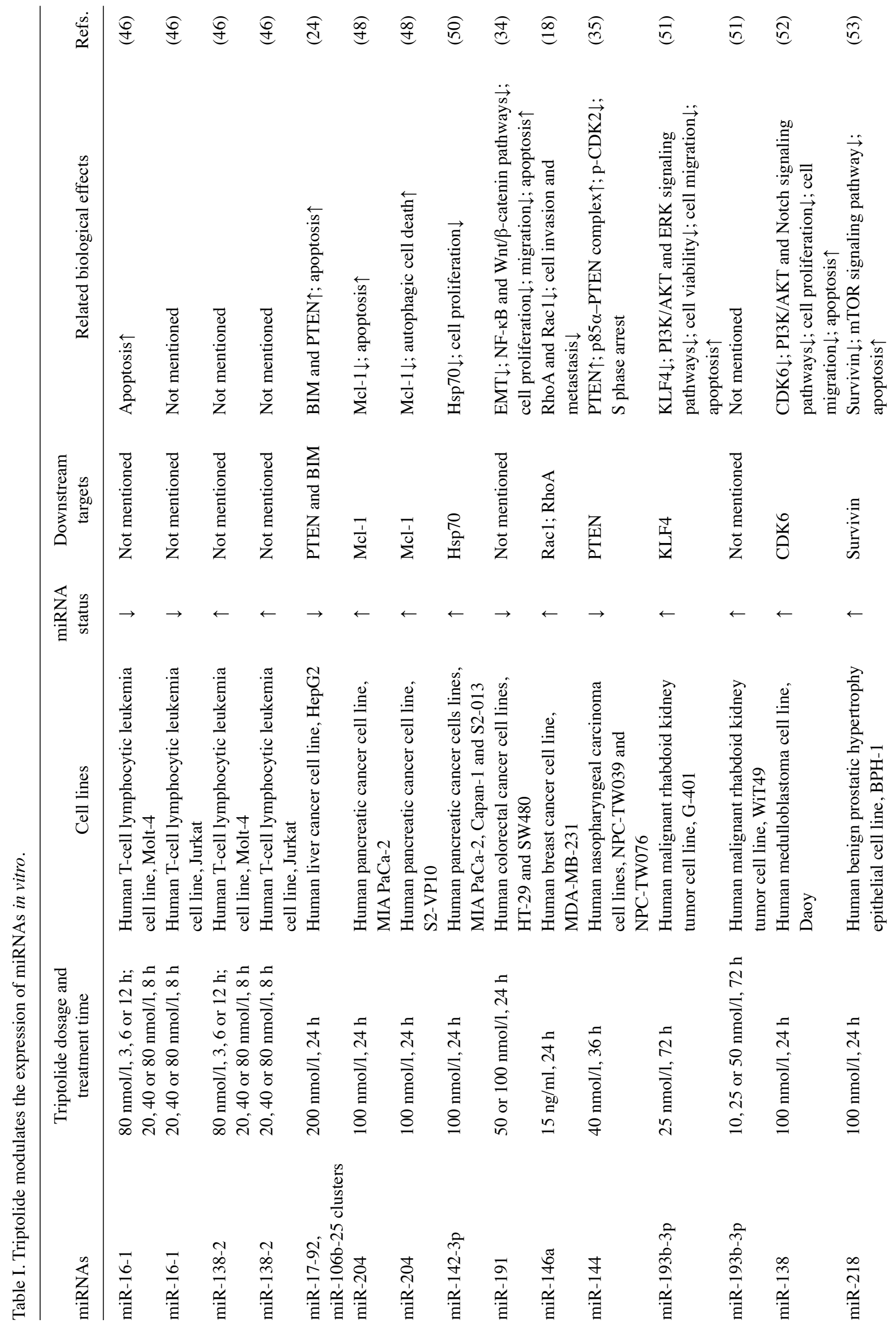




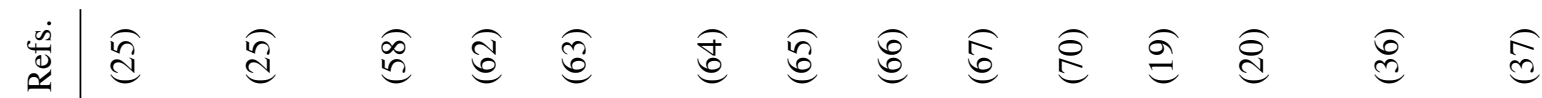

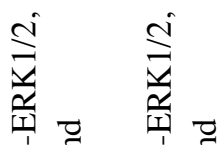

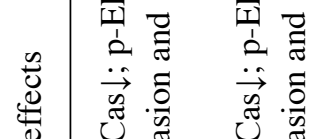

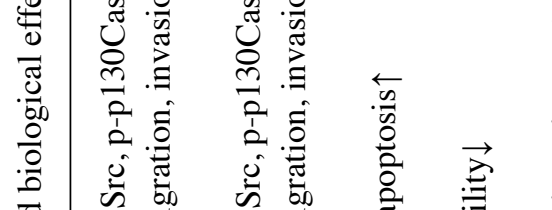

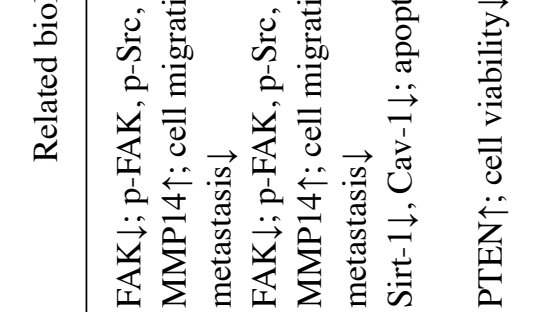

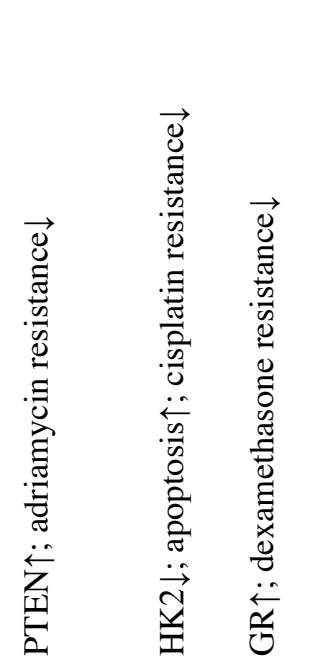

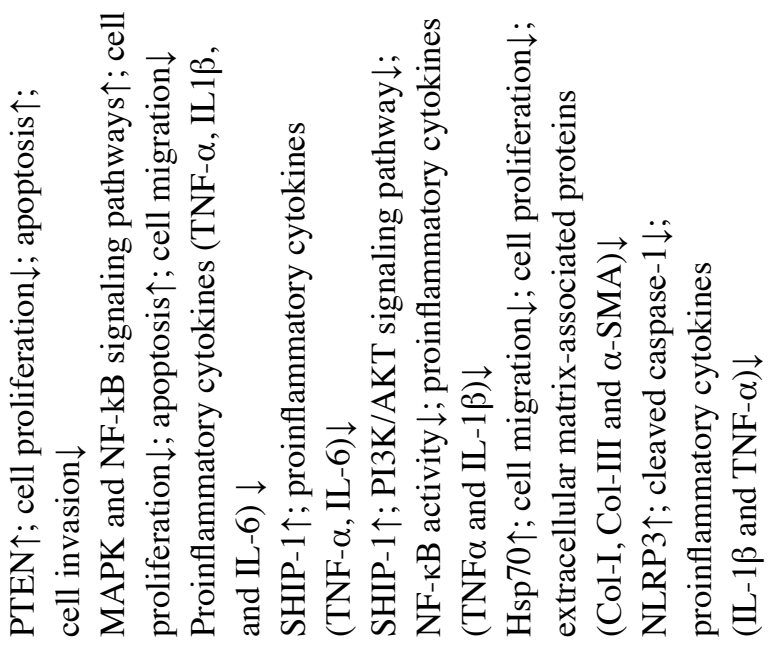

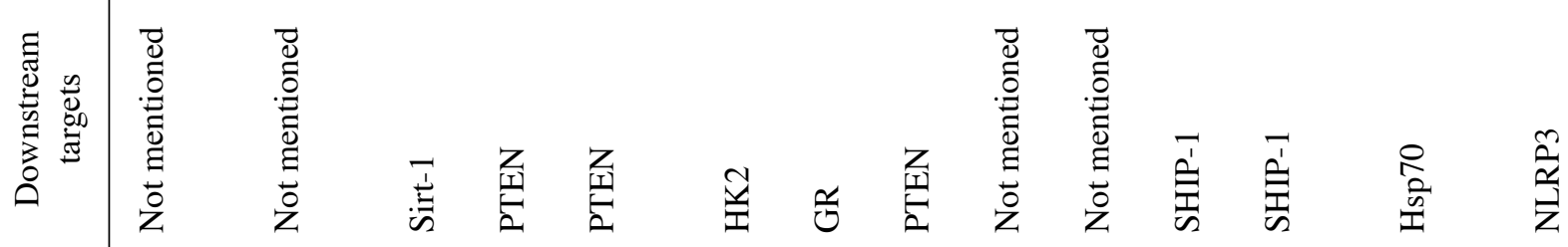

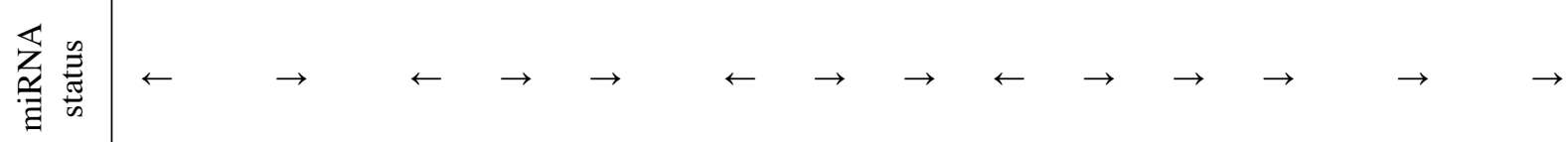

II

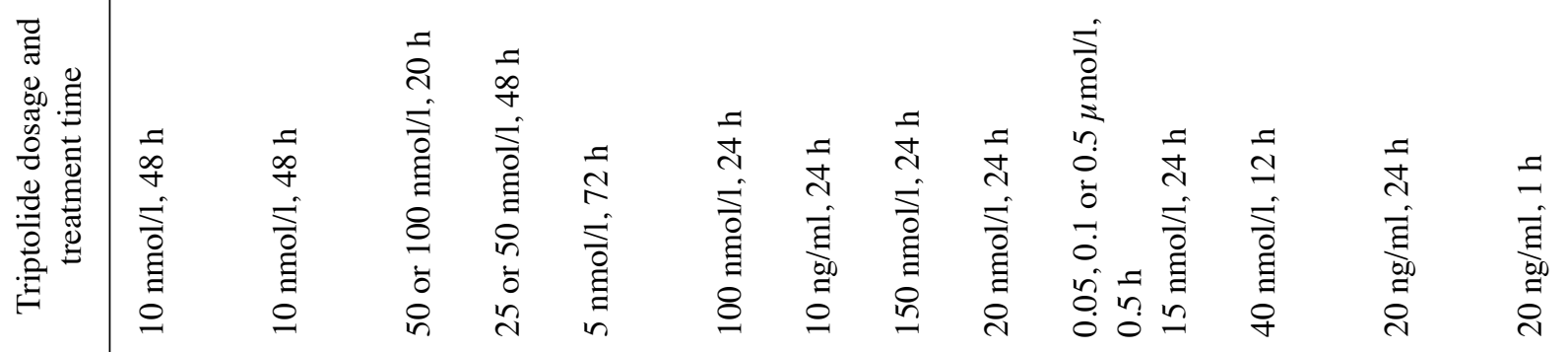

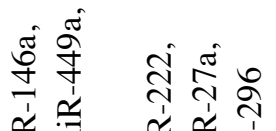

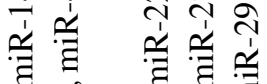

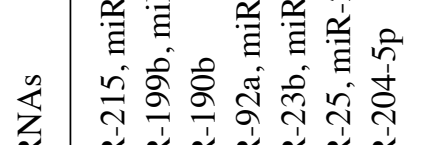

Z,

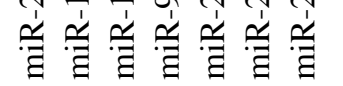

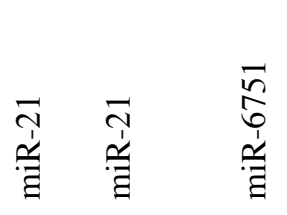

를

กิ 


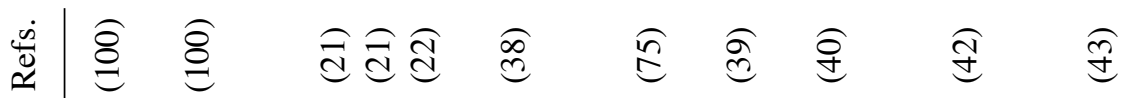

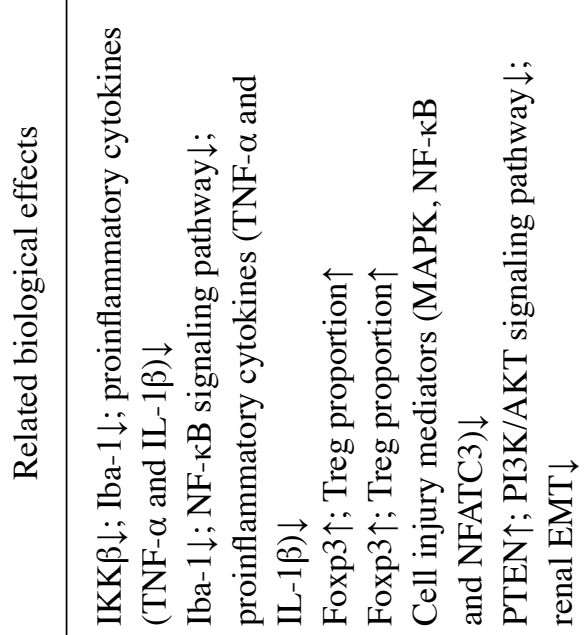

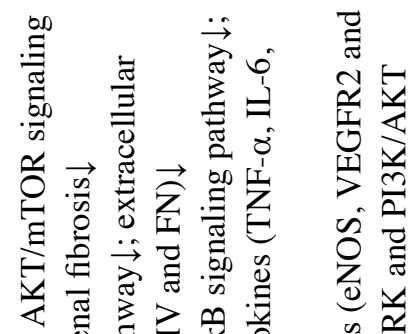

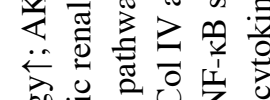

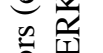

政:

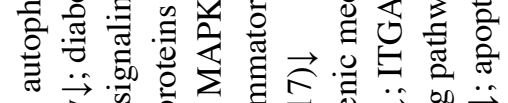

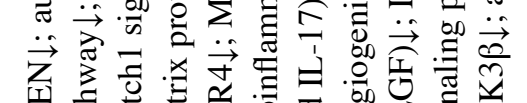

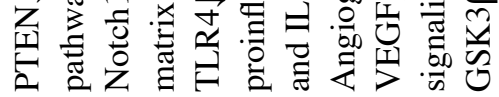

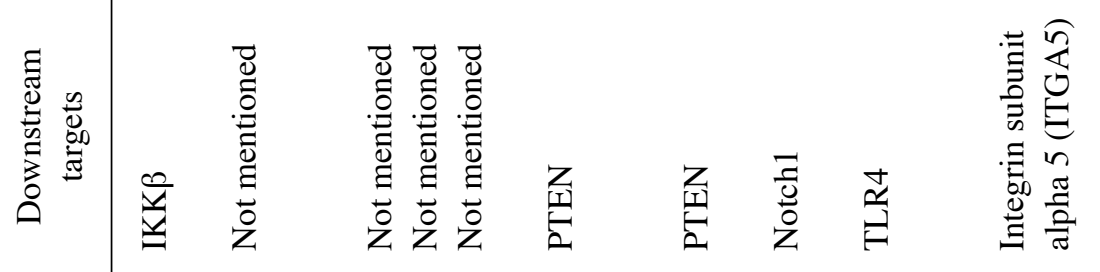

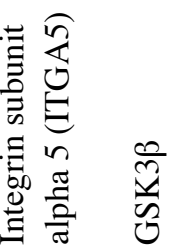

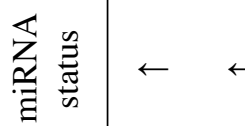

产

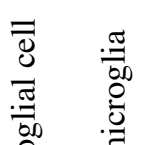

童

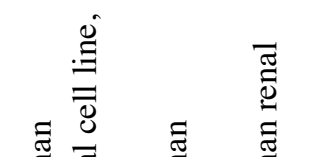

䍬

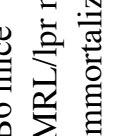

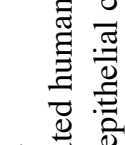

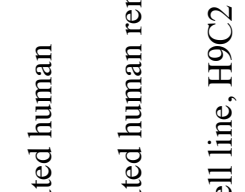

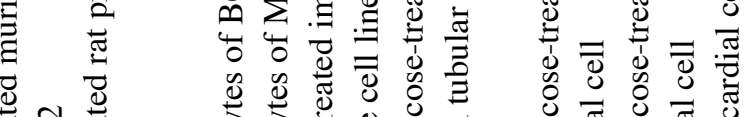

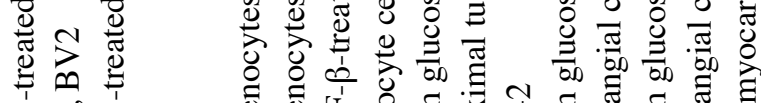

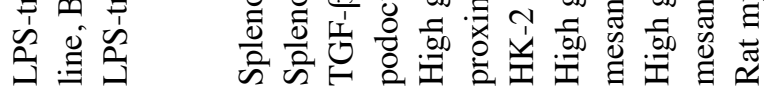

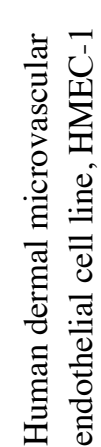

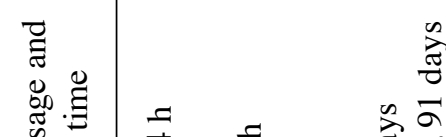

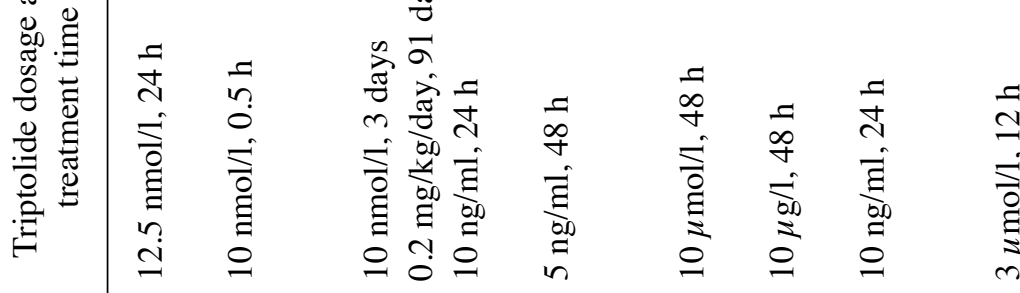

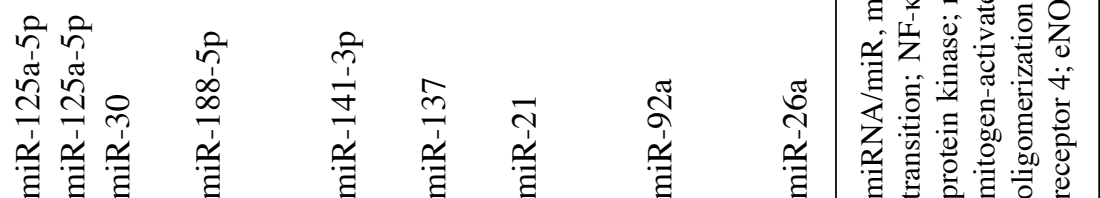




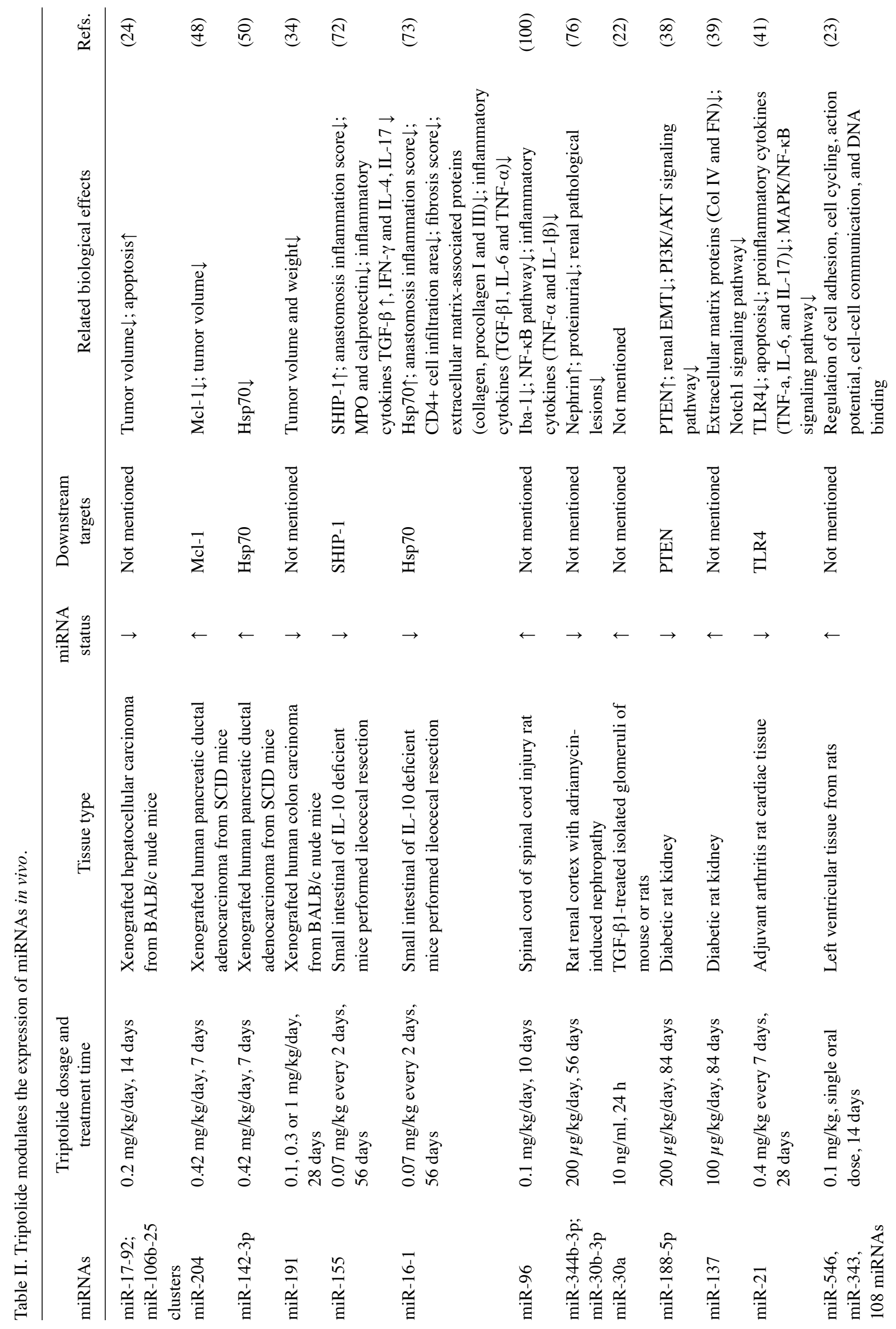




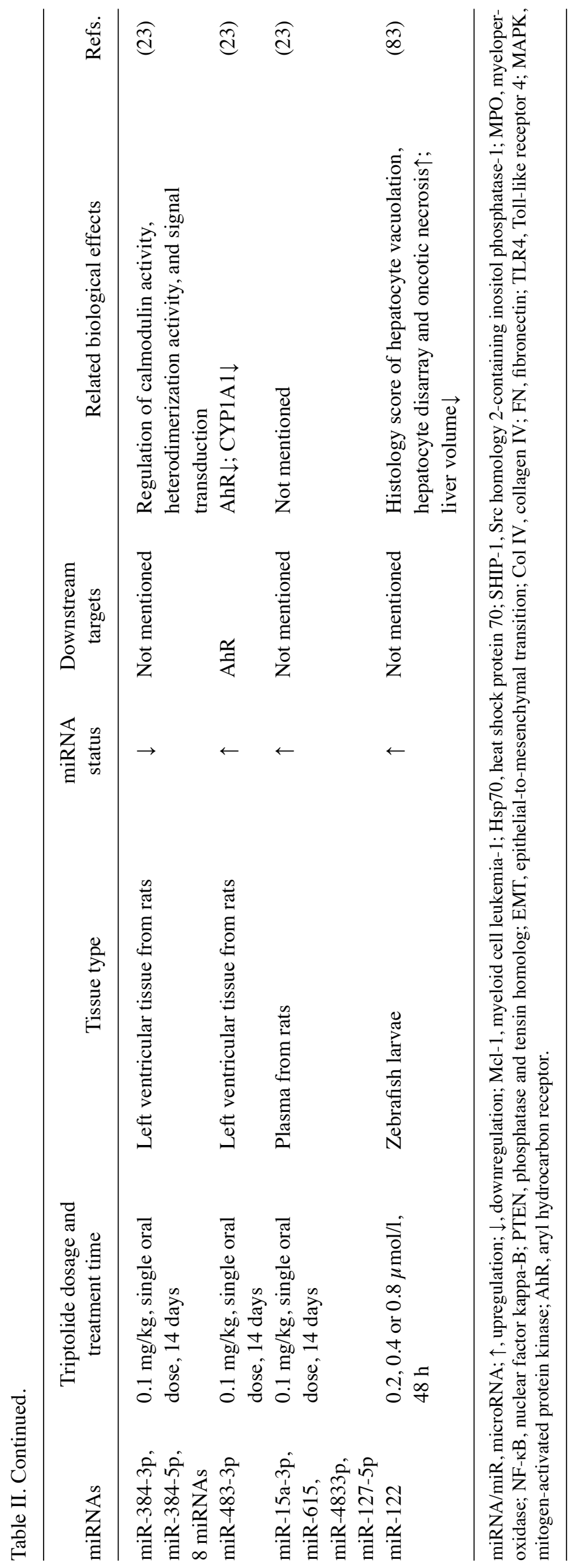


inhibits the proliferation of nephroblastoma and medulloblastoma cells, and benign prostatic epithelial cells. In addition, triptolide inhibits the migratory ability of these cells but promotes apoptosis by upregulating the expression levels of miR-193b-3p, miR-138 and miR-218 (51-53). The latter activities involving miRNAs corresponded to inactivation of the phosphatidylinositol 3 kinase (PI3K)/AKT and extracellular regulated protein kinase (ERK) signaling pathways by downregulating Kruppel-like factor, inactivating the Notch signaling pathway, as well as suppressing CDK6 expression, or negatively regulating survivin and inactivating the mammalian target of rapamycin (mTOR) signaling pathway, respectively (51-53).

Sequencing data indicate that triptolide markedly alters the expression profiles of miRNAs in human non-small cell lung cancer cells. miRNAs associated with cell motility, such as miR-146a, miR-23b and miR-199b (54-56), are significantly upregulated or downregulated, and subsequent studies have validated that triptolide notably decreases lung cancer cell migration, invasion and metastasis by suppressing focal adhesion kinase expression and disrupting its downstream signaling pathways (25). Furthermore, treatment with triptolide causes a dose-dependent upregulation of miR-204-5p expression, along with decreased expression of its target, SIRT-1, a member of the class III histone deacetylase family required for caveolin-1 (Cav-1) expression (57), thereby coupling Cav-1 downregulation with activation of classical AKT/Bax-mediated apoptosis in non-small cell lung cancer cells (58).

Drug resistance is one of the main reasons for therapy failure in cancer treatment (59). miRNAs are critical regulators of molecular pathways implicated in cancer drug resistance (60). miR-21 is highly expressed and associated with disease progression and multidrug-resistance in different types of cancer (61). Triptolide notably decreases miR-21 expression in non-small cell lung cancer cells, and increases PTEN protein expression, which acts as a tumor suppressor and participates in tumor occurrence and development, and decreases cell proliferation and enhances apoptosis (62). However, ectopic miR-21 expression rescues the effect of triptolide on PTEN protein expression and cell viability, suggesting that triptolide mediates the decrease in miR-21 expression, which in turn promotes cell death by upregulating PTEN expression (62). Furthermore, triptolide significantly enhances adriamycin-induced cytotoxicity by decreasing miR-21 expression and increasing PTEN expression, and reverses drug resistance to human chronic myeloid leukemia cells (63).

In cisplatin-resistant human ovarian cancer cells, upregulation of miR-6751 expression via triptolide decreases hexokinase 2 protein expression, which confers resistance to cisplatin by enhancing autophagic activity, and sensitizes cells to the proapoptotic effect of cisplatin (64). A similar synergistic proapoptotic effect was detected following combined treatment with triptolide and dexamethasone in human multiple myeloma cells, which has the ability to overcome the glucocorticoid resistance of these cells by enhancing glucocorticoid receptor expression by inhibiting miR-142-5p and miR-181a expression (65). Furthermore, miR-181a expression is notably attenuated in osteosarcoma cells following treatment with triptolide, which directly upregulates PTEN expression, whereas transfection with miR-181a mimics restores PTEN expression, and decreases the inhibitory effect of triptolide on osteosarcoma cell proliferation and invasion, suggesting the anti-osteosarcoma properties of triptolide depended on the regulation of miR-181a and its targeting of the PTEN gene (66). Conversely, upregulated miR-181a expression participates in the suppressive effect of triptolide against human neuroblastoma cell proliferation and migration, and via activation of the mitogen-activated protein kinase (MAPK) and NF- $\mathrm{B}$ signaling pathways (67). Thus, triptolide can upregulate or downregulate the expression of specific miRNAs, influence downstream targeting signaling pathways, and thus exert antitumor activities (Fig. 1).

miRNAs involved in the anti-inflammatory and immunosuppressive activities of triptolide. Several miRNAs are substantially activated by inflammatory stimuli, such as the Toll-like receptor (TLR), ligand lipopolysaccharide (LPS) and components of the inflammatory processes by post-transcriptional regulation of either signal transduction proteins of inflammatory pathways or specific inflammatory cytokines (68). For example, miR-155, which is implicated in the pathogenesis of inflammatory diseases (69), has prompted investigation on the association between triptolide and miR-155 in these inflammatory diseases. cDNA array and northern blot analysis have demonstrated that the expression of inflammatory cytokine, as well as miR-155 are markedly upregulated in macrophages following LPS stimulation, whereas triptolide attenuates the induction of these genes in a dose-dependent manner (70).

Similar observations were obtained in monocytes from patients with rheumatoid arthritis (19), whereby overexpression of miR-155 reverses the inhibitory effect of triptolide on LPS-induced interleukin (IL)- 6 and tumor necrosis factor- $\alpha$ production, and antagonizes the effect of triptolide on Src homology 2-containing inositol phosphatase-1 (SHIP-1), which is a target of miR-155 and functions as a potent inhibitor of several inflammatory pathways (71). Thus, it has been proposed that triptolide inhibits miR-155 expression, which negatively affects its downstream target, SHIP-1, and suppresses the inflammatory response stimulated by LPS.

The miR-155/SHIP-1 axis plays a critical role in triptolide-induced improvement on the symptoms of other inflammatory diseases. Inhibiting the miR-155/SHIP-1 axis via triptolide suppresses $\mathrm{NF}-\kappa \mathrm{B}$ activity via the PI3K/AKT pathway, which significantly inhibits microglial activation and stimulates inflammatory cytokines stimulated by prion-like preformed fibril (20).

Triptolide has also been reported to suppress miR-155 expression and simultaneously promote SHIP-1 expression in the small intestine, particularly in the anastomosis of IL-10 deficient mice subjected to ileocecal resection (72). These effects are also associated with decreased levels of inflammatory cytokines, and eventually exert therapeutic effects on Crohn's disease, an inflammatory bowel disease (72). Studies on Crohn's disease have reported that triptolide effectively reverses upregulated miR-16-1 expression and downregulated Hsp70 expression at the anastomosis sites in IL-10 deficient mice, as well as in patients with Crohn's disease, which represents a protective mechanism against postsurgical inflammation and anastomotic fibrosis $(37,73)$. 


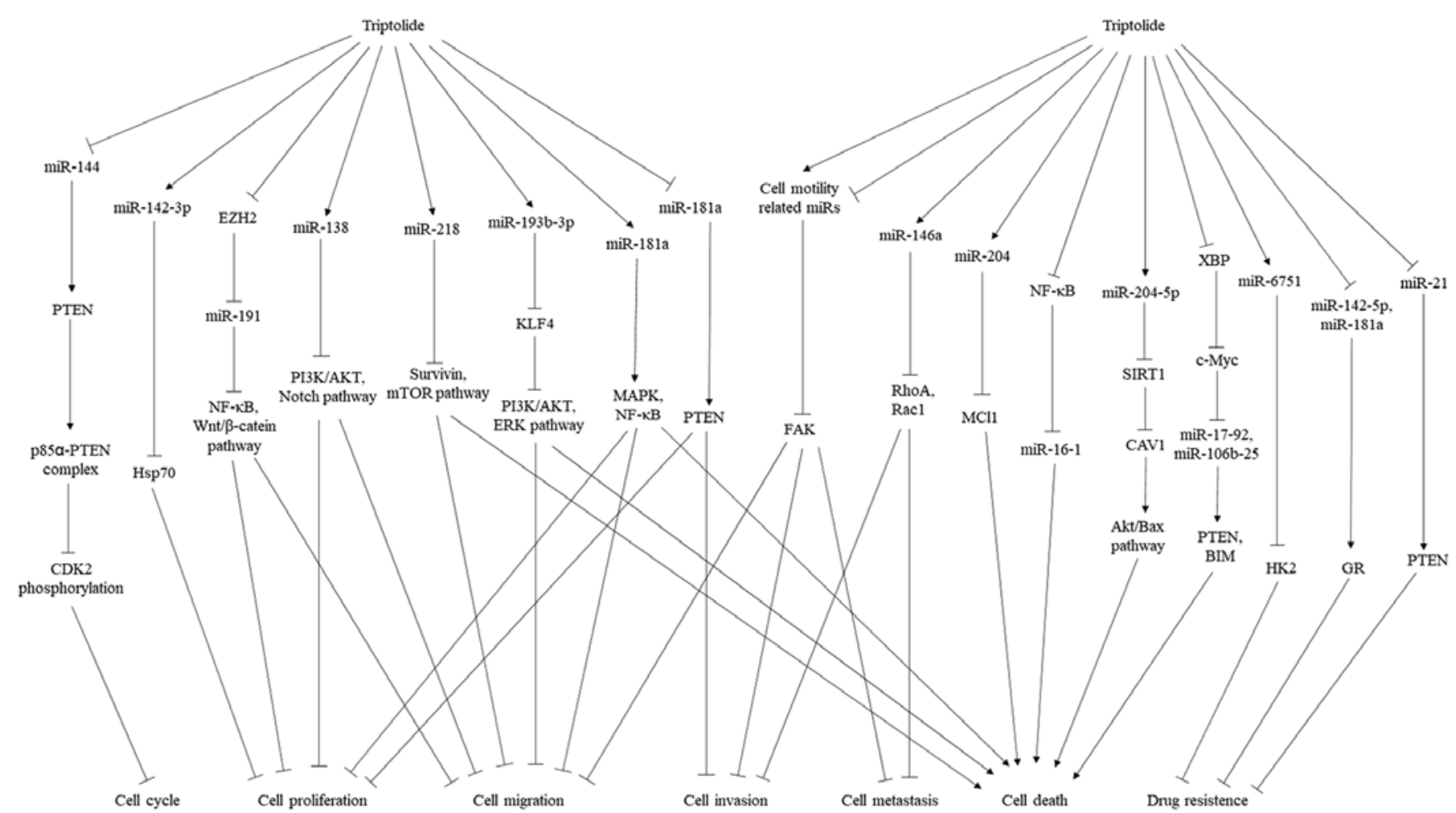

Figure 1. miRNAs involved in the antitumor activity of triptolide. Through upregulation and downregulation of specific miRNAs, triptolide affects downstream signaling pathways, which induces tumor cell cycle arrest, interferes with cell proliferation, suppresses cell migration, invasion and metastasis, enhances cell death and reverses drug resistance. miRNA, microRNA; PTEN, phosphatase and tensin homolog; CDK, cyclin-dependent kinase; Hsp, heat shock protein; $\mathrm{EZH} 2$, enhancer of zeste homolog 2; NF-кB, nuclear factor kappa-B; PI3K, phosphatidylinositol 3 kinase; AKT, protein kinase B; mTOR, mammalian target of rapamycin; KLF4, Kruppel-like factor; ERK, extracellular regulated protein kinase; Cav-1, caveolin-1; HK2, hexokinase 2; GR, glucocorticoid receptor.

With regards to the effects on osteoarthritis, downregulation of miR-20b expression following treatment with triptolide notably upregulates its target inflammasome-related gene, nucleotide-binding oligomerization domain-like receptor family pyrin domain-containing protein 3 , which limits the activation of caspase- 1 and subsequently inhibits the maturation of inflammatory cytokines, thus preventing the development of osteoarthritis (41). In the treatment of spinal cord injury (SCI), the anti-inflammatory activity of triptolide is mediated by upregulated miR-96 expression, which inactivates NF- $\kappa B$ by negatively regulating the inhibitor of NF- $\kappa B$ kinase subunit $\beta$ expression, and decreases inflammatory cytokine levels in LPS-induced primary microglia and spinal cord tissues of SCI rats (42).

Triptolide is frequently used as an immunosuppressive compound in the treatment of chronic autoimmune diseases, including systemic lupus erythematosus (SLE) (12). Recently, a novel miRNA target was identified following treatment of SLE by triptolide. Triptolide was demonstrated to markedly increase miR-125a-5p expression, as well as the percentage of regulatory $\mathrm{T}$ cells (Treg), which are important in modulating self-tolerance and autoimmunity (74). Conversely, miR-125a-5p inhibitor significantly abrogates the effects of triptolide on Treg, suggesting that triptolide stimulates Treg activation via miR-125a-5p, and thereby alleviates the clinical and histological symptoms observed in the SLE mouse model (21). Taken together, these findings suggest that changes in the expression levels of specific miRNAs contribute to the anti-inflammatory and immunosuppressive properties of triptolide.
miRNAs involved in the renal protective and cardioprotective activities oftriptolide.Increasing evidencesuggest thattriptolide exhibits renal protective effects by regulating the expression of miRNAs $(22,38,39,75,76)$. In adriamycin-induced nephropathy rat models, elevated expression levels of miR-344b-3p and $\mathrm{miR}-30 b-3 p$ were observed, the effects of which were reversed following treatment with triptolide. Triptolide also increases the levels of nephrin protein, which is involved in the maintenance of the glomerular filtration barrier structure in the kidney cortex, thereby attenuating podocyte damage and partially improving renal function (76). Thus, it has been speculated that miR-344b-3p and miR-30b-3p are involved in the protective effect of triptolide towards podocytes from adriamycin-induced nephropathy (76). In the transforming growth factor- $\beta$ (TGF- $\beta$ )-induced podocyte injury model, the presence of triptolide completely reversed TGF- $\beta$-induced miR-30 downregulation, suppressed TGF- $\beta$-stimulated activation of downstream damaging pathways, including MAPK, NF- $\kappa \mathrm{B}$ and calcineurin/NFATC3, and alleviated podocyte injury in vitro and ex vivo (22).

During the development of diabetic kidney disease (DKD), miRNAs are closely associated with multiple pathological modifications (77). Triptolide notably mitigates the impaired renal function by exerting a therapeutic effect on DKD through the regulation of miRNA-mediated signaling pathways $(38,75)$. For example, triptolide significantly reverses the increase in miR-188-5p expression induced by high glucose in human proximal tubular epithelial cells and diabetic kidneys, which enhances the expression of action target PTEN, and 
inactivates the downstream PI3K/AKT signaling pathway and inhibits renal epithelial-to-mesenchymal transition in DKD (38). Similarly, downregulation of miR-141-3p expression via triptolide affects the target PTEN protein in human renal mesangial cells, under high glucose, with an opposite tendency. In addition, triptolide-induced autophagic activation and fibrosis alleviation in association with the activation of the PTEN/AKT/mTOR pathway is blocked following overexpression of miR-141-3p (75).

The miR-137/Notch1 pathway prevents glomerulosclerosis under diabetic conditions (39). Unlike miR-188-5p and miR-141-3p, miR-137 expression significantly decreases in high glucose-incubated renal mesangial cells and in diabetic rat kidney tissues, but returns to normal levels following treatment with triptolide (39). Triptolide inactivates the Notch1 pathway reliance on miR-137, which suppresses extracellular matrix protein accumulation of collagen IV and fibronectin, thus improving DKD by protecting against glomerulosclerosis (39).

The cardioprotective activity of triptolide has been attributed to the changes in miR-21 expression. Treatment with triptolide markedly decreases miR-21 expression, inactivates the TLR4/MAPK/NF- $\kappa \mathrm{B}$ signaling pathway and prevents cell apoptosis in LPS-treated myocardial cells, as well as in cardiac tissues from adjuvant arthritis rat models $(40,41)$. Collectively, these findings confirm the regulatory role of miRNAs in the renal protective and cardioprotective activities of triptolide.

miRNAs involved in the antiangiogenesis activity of triptolide. A key feature of atherosclerosis is the dysregulated progression of endothelial cell angiogenesis within the plaques, a process that is regulated by several miRNAs, particularly miR-92a (78). miR-92a blocks angiogenesis both in vitro and in vivo (79), and participates in the inhibitory effect of triptolide in atherosclerosis. In human dermal microvascular endothelial cells, triptolide effectively induces miR-92a expression in a dose-dependent manner, and impedes the production of integrin subunit $\alpha 5$ (ITGA5), which is a direct target of miR-92a (42). Overexpression of ITGA5 inactivates the ERK and PI3K/AKT signaling pathways, as well as the accumulation of a number of angiogenesis-related factors, such as endothelial nitric oxide synthase, VEGF receptor-2 and VEGF, which inhibits angiogenesis (42). These effects are reversed following ITGA5 knockdown (42). Thus, miR-92a acts as a crucial mediator in the antiangiogenesis activity of triptolide by inactivating the ERK and PI3K/AKT signaling pathways following downregulation of ITGA5 expression.

miRNAs involved in the multiorgan toxicity of triptolide. Several miRNAs, such as miR-122 and miR-26a, are involved in the multiorgan toxicity observed following treatment with triptolide, and are considered sensitive early warning indicators (80). Oral administration of triptolide in male rats led to cardiac dysfunction and myocardial cell death. These effects were associated with at least a 2-fold increase in the expression levels of 108 miRNAs, as well as a 2-fold decrease in the expression levels of eight miRNAs in heart tissue samples. Furthermore, changes in plasma miRNAs were also detected (81). Among these, 28 miRNAs were predicted to simultaneously regulate the expression of aryl hydrocarbon receptor (AhR), which is a transcription factor that is closely associated with cardiac pathophysiology (81). Another study confirmed that triptolide significantly decreases myocardial and plasma AhR levels, as well as its downstream gene, CYPIAl (23).

miR-122 expression is significantly upregulated in adult zebrafish or mice livers following treatment with liver toxicants, including acetaminophen or tamoxifen (82). A similar trend has been observed in zebrafish larvae following treatment with triptolide, which causes hepatic injury (83), which is considered to be a crucial event resulting from deregulated hepatic function caused by altered miR-122 expression (84). Taken together, these findings suggest that miR-122 may be used as a diagnostic predictor and an attractive therapeutic target for the hepatotoxicity activity of triptolide.

miR-26a expression is upregulated in triptolide-induced reproductive toxicity in mouse Leydig cells (43). This results in cytotoxicity via inhibition of its downstream target, glycogen synthase kinase-3 $\beta$, which possesses antiapoptotic effects (43). Collectively, these findings indicate the association between miRNAs and the multiorgan toxicity of triptolide.

\section{Molecular mechanisms underlying regulation of miR- NAs by triptolide}

The regulation of the expression of miRNAs by triptolide is partly mediated by specific transcription factors. Triptolide has been reported to interfere with TGF- $\beta$-induced Smad $2 / 3$ phosphorylation and activation, and prevents phosphorylated protein binding to Smad4 and their subsequent translocation to nuclei where they are known to regulate gene expression as transcription factors, and thereby completely restore miR-30 downregulation in podocytes (22). As a multifunctional transcription factor, $\mathrm{NF}-\kappa \mathrm{B}$ positively and negatively regulates the expression of miRNAs (85). Treatment with triptolide decreases the expression and nuclear accumulation of $\mathrm{NF}-\kappa \mathrm{B}$ in a dose-dependent manner, accompanied by the differential expression of 23 miRNA genes in lymphocytic leukemic cell lines, suggesting that triptolide-induced cytotoxic effects may occur by inhibiting NF- $\kappa \mathrm{B}$ transcriptional activity, and consequently influencing the expression of miRNAs (46). c-Myc also plays a critical role in repressing two oncogenic miRNA clusters by triptolide in hepatocellular carcinoma cells (24). Through direct binding to the E-box element in the promoter region of MCM7, c-Myc transactivates both miR-7-92 and miR-106b-25, which function as oncogenes in cancer initiation and progression (86). Triptolide significantly antagonizes the transcription of these two miRNA clusters by targeting c-Myc, and XPB (also known as ERCC3) is involved in this process (24). XPB is a subunit of general transcription factor TFIIH, which is essential for RNA polymerase II-dependent transcription initiation and nucleotide excision repair (87). It has been reported that triptolide covalently binds to the Cys342 residue of XPB, the largest subunit of the general transcription factor TFIIH (88), and impedes its ATPase activity, inhibiting RNA polymerase II mediated transcription (89). Triptolide also acts as an inhibitor of RNA polymerase II by selectively activating CDK7, and subsequently by triggering proteasome-dependent degradation of hyperphosphorylated Rpb1, which is the largest RNA polymerase II subunit (90). On the other hand, triptolide directly suppresses the recruitment 
of B-related factor 1 to TFIIIB complex, an essential transcription initiation factor of RNA polymerase III (91), and significantly inhibits RNA polymerase III transcription (92). Based on these observations and the fact that miRNA genes are transcribed by RNA polymerase II or III, it is reasonable to speculate that the inhibition of RNA polymerase II and III mediated general transcription underlies miRNAs regulation by triptolide.

Triptolide may also regulate the expression of miRNAs via an enhancer of zeste homolog 2 (EZH2)-involved mechanism. EZH2, a well-known histone methyltransferase (93), is capable of binding to the promoter regions of miRNAs genes and catalyzing histone $\mathrm{H} 3$ trimethylation, resulting in the transcriptional silencing of miRNAs genes (94). It has been proven that $\mathrm{EZH} 2$ is a target for triptolide in prostate cancer and multiple myeloma cells (95), and a recent study demonstrated that treatment with triptolide significantly downregulates miR-191 expression in colon carcinoma cells in an EZH2-dependent manner, suggesting a modulatory activity of triptolide on the expression of miRNAs at the epigenetic level (34).

The regulation of miRNAs by triptolide may be ascribed to the autophagy pathway. Autophagy can be modulated by triptolide through multiple machineries and signaling pathways, such as oxidative stress, cytoplasmic calcium and the AKT/mTOR/p70S6K pathway (13). miRNAs also play vital roles in autophagy as they can target autophagy-related genes or other related regulators, and participate in regulating the dynamic process of autophagy (96). Triptolide has been reported to significantly decrease miR-141-3p expression, which directly acts on PTEN, and thereby reverses the induced autophagy in high glucose treated human mesangial cells and in DKD rats (75). Conversely, autophagy selectively regulates miRNA homeostasis, which is activated by promoting autophagy receptor-mediated degradation of miRNA pathway components, including DICER and AGO2, further proving an association between autophagy and miRNAs (97). Although the molecular mechanisms involved in the role of autophagy in triptolide regulation of miRNAs remain unclear, it is possible that autophagy may play a functional role, and the precise molecular targets and regulatory networks remain to be elucidated. Collectively, these findings suggest that the expression of triptolide-regulated miRNAs is mediated by multiple intracellular components and molecular mechanisms.

\section{Conclusions and future perspective}

Traditional Chinese medicines have been effectively used to cure various diseases. Thus, investigating the molecular mechanisms underlying their activities is highly warranted. As a biologically active ingredient derived from the Chinese herb, Tripterygium wilfordii Hook F., recent studies have demonstrated that triptolide exerts effects on the expression of a series of endogenous miRNAs, which in turn employ several downstream cellular factors to achieve its multiple pharmacological activities, highlighting miRNAs as critical mediators for triptolide-induced effects $(18,20,21,23,34-43)$. However, determining the exact role of these miRNAs is limited by the in vitro models offered by these studies. Haploid cells are effective tools to study gene function due to having one set of chromosomes $(98,99)$. Thus, prospective studies will aim to use haploid cells to screen novel miRNAs for specific functions following treatment with triptolide, and additional evidence from in vivo experiments will validate the conclusions. In addition, regulation of miRNA expression is usually cell- or tissue-specific, and as precise base pairing between miRNA and their corresponding mRNA targets is not required. A single miRNA may simultaneously target several mRNAs, whereas one mRNA can be regulated by different miRNAs $(28,30,33)$. Triptolide may affect PTEN expression by regulating the expression of several miRNAs, including miR-21 (62,63), miR-181a (66), miR-188-5p (38), miR-144 (35), miR-141-3p (75), miR-17-92 and miR-106b-25 clusters (24). miR-21 is a common target when triptolide controls the expression of both TLR4 and PTEN $(40,41,62,63)$. Thus, the intricate complexity and integration of the activity of miRNAs present challenges in identifying their function and regulatory pathways. Supplementary bioinformatics tools may provide integrated analyses of these complicated networks that participate in the pharmacological activities of triptolide. Prospective studies are required to investigate whether miRNAs play roles in other pharmacological activities of triptolide.

In conclusion, specific miRNAs have been identified as primary targets when triptolide displays multiple pharmacological effects. These findings also suggest that triptolide can serve as a novel molecular probe for studying miRNAs. A comprehensive understanding of the regulatory pathways and specific functions of these miRNAs will help determine the underlying molecular mechanisms of triptolide and provide more effective strategies for drug development and disease treatment.

\section{Acknowledgements}

Not applicable.

\section{Funding}

The present review was supported by the Applied Basic Research Program of Science and Technology Department of Shanxi Province (grant no. 201801D121357), the Research Project of Shanxi Provincial Health and Family Planning Commission (grant no. 201601114) and the Research Fund from Shanxi Key Laboratory of Innovative Drug for Treatment of Serious Diseases Basing on the Chronic Inflammation (grant no. SXIDL-2018-08).

\section{Availability of data and materials}

Not applicable.

\section{Authors' contributions}

YW conceived and supervised the present study. KZ drafted the initial manuscript. YC, BH, RL and YW reviewed the manuscript for important intellectual content. All authors have read and approved the final manuscript.

\section{Ethics approval and consent to participate}

Not applicable. 


\section{Patient consent for publication}

Not applicable.

\section{Competing interests}

The authors declare that they have no competing interests.

\section{References}

1. Auyeung KK, Han QB and Ko JK: Astragalus membranaceus: A review of its protection against inflammation and gastrointestinal cancers. Am J Chin Med 44: 1-22, 2016.

2. Wang Z, Xia Q, Liu X, Liu W, Huang W, Mei X, Luo J, Shan M, Lin R, Zou D and Ma Z: Phytochemistry, pharmacology, quality control and future research of Forsythia suspensa (Thunb.) Vahl: A review. J Ethnopharmacol 210: 318-339, 2018.

3. Shi JF, Luo YY, Li JX, Luo RF, Chen L, Li J, Zhang JM and Fu CM: Research progress on anti-tumor effects and mechanisms of triptolide and its combined application. China J Chin Mater Med 44: 3391-3398, 2019.

4. Noel P, Von Hoff DD, Saluja AK, Velagapudi M, Borazanci E and Han M: Triptolide and its derivatives as cancer therapies. Trends Pharmacol Sci 40: 327-341, 2019.

5. Yan P and Sun X: Triptolide: A new star for treating human malignancies. J Cancer Res Ther 14 (Suppl): S271-S275, 2018.

6. Huang G, Yuan K, Zhu Q, Zhang S, Lu Q, Zhu M, Sheng H, Yu R, Luo $\mathrm{G}$ and $\mathrm{Xu} \mathrm{A}$ : Triptolide inhibits the inflammatory activities of neutrophils to ameliorate chronic arthritis. Mol Immunol 101 210-220, 2018

7. Huang SH, Lin GJ, Chu CH, Yu JC, Chen TW, Chen YW, Chien MW, Chu CC and Sytwu HK: Triptolide ameliorates autoimmune diabetes and prolongs islet graft survival in nonobese diabetic mice. Pancreas 42: 442-451, 2013.

8. Zheng CX, Chen ZH, Zeng CH, Qin WS, Li LS and Liu ZH: Triptolide protects podocytes from puromycin aminonucleoside induced injury in vivo and in vitro. Kidney Int 74: 596-612, 2008.

9. Yu H, Shi L, Zhao S, Sun Y, Gao Y, Sun Y and Qi G: Triptolide attenuates myocardial ischemia/reperfusion injuries in rats by inducing the activation of $\mathrm{Nrf} / \mathrm{HO}-1$ defense pathway. Cardiovasc Toxicol 16: 325-335, 2016.

10. Xi C, Peng S, Wu Z, Zhou Q and Zhou J: Toxicity of triptolide and the molecular mechanisms involved. Biomed Pharmacother 90 531-541, 2017.

11. Chen SR, Dai Y, Zhao J, Lin L, Wang Y and Wang Y: A mechanistic overview of triptolide and celestrol, natural products from Tripterygium wilfordii Hook F. Front Pharmacol 9: 104, 2018.

12. Yuan K, Li X, Lu Q, Zhu Q, Jiang H, Wang T, Huang G and $\mathrm{Xu}$ A: Application and mechanisms of triptolide in the treatment of inflammatory diseases-a review. Front Pharmacol 10: 1469, 2019.

13. Wei YM, Wang YH, Xue HQ, Luan ZH, Liu BW and Ren JH: Triptolide, A potential autophagy modulator. Chin J Integr Med 25: 233-240, 2019.

14. Jin W, Wang J, Liu CP, Wang HW and Xu RM: Structural basis for pri-miRNA recognition by Drosha. Mol Cell 78: 423-433, 2020 .

15. Olejniczak M, Kotowska-Zimmer A and Krzyzosiak W Stress-induced changes in miRNA biogenesis and functioning. Cell Mol Life Sci 75: 177-191, 2018.

16. Dexheimer PJ and Cochella L: MicroRNAs: From mechanism to organism. Front Cell Dev Biol 8: 409, 2020.

17. Rupaimoole R and Slack FJ: MicroRNA therapeutics: Towards a new era for the management of cancer and other diseases. Nat Rev Drug Discov 16: 203-222, 2017.

18. Liu Q, Wang W, Li F, Yu D, Xu C and Hu H: Triptolide inhibits breast cancer cell metastasis through inducing the expression of miR-146a, a negative regulator of Rho GTPase. Oncol Res 27 1043-1050, 2019

19. Peng A, Huang $X$, Liu R, Wang $X$ and Zhuang J: Triptolide inhibits the inflammatory response of monocytes from rheumatoid arthritis patients by regulating miR-155. Chin J Cell Mol Immunol 30: 635-638, 2014.

20. Feng Y, Zheng C, Zhang Y, Xing C, Cai W, Li R, Chen J and Duan Y: Triptolide inhibits preformed fibril-induced microglial activation by targeting the microRNA155-5p/SHIP1 pathway. Oxid Med Cell Longev 2019: 6527638, 2019.
21. Zhao X, Tang X, Yan Q, Song H, Li Z, Wang D, Chen H and Sun L Triptolide ameliorates lupus via the induction of miR-125a-5p mediating Treg upregulation. Int Immunopharmacol 71: 14-21, 2019.

22. Yang Q, Sun M, Chen Y, Lu Y, Ye Y, Song H, Xu X, Shi S and Wang J: Triptolide protects podocytes from TGF- $\beta$-induced injury by preventing miR-30 downregulation. Am J Transl Res 9: 5150-5159, 2017

23. Wang SR, Chen X, Ling S, Ni RZ, Guo H and Xu JW: MicroRNA expression, targeting, release dynamics and early-warning biomarkers in acute cardiotoxicity induced by triptolide in rats. Biomed Pharmacother 111: 1467-1477, 2019.

24. Li SG, Shi OW, Yuan LY, Qin LP, Wang Y, Miao YQ, Chen Z, Ling CQ and Qin WX: C-Myc-dependent repression of two oncogenic miRNA clusters contributes to triptolide-induced cell death in hepatocellular carcinoma cells. J Exp Clin Cancer Res 37: 51, 2018.

25. Reno TA, Kim JY and Raz DJ: Triptolide inhibits lung cancer cell migration, invasion, and metastasis. Ann Thorac Surg 100: $1817-1825,2015$

26. Kalla R, Ventham NT, Kennedy NA, Quintana JF, Nimmo ER, Buck AH and Satsangi J: MicroRNAs: New players in IBD. Gut 64: 504-517, 2015.

27. Michlewski G and Caceres JF: Post-transcriptional control of miRNA biogenesis. RNA 25: 1-16, 2019.

28. Saliminejad K, Khorram Khorshid HR, Soleymani Fard S and Ghaffari SH: An overview of microRNAs: Biology, functions, therapeutics, and analysis methods. J Cell Physiol 234: 5451-5465, 2019

29. Vishnoi A and Rani S: miRNA biogenesis and regulation of diseases: An overview. Methods Mol Biol 1509: 1-10, 2017

30. Yates LA, Norbury CJ and Gilbert RJ: The long and short of microRNA. Cell 153: 516-519, 2013.

31. Turner MJ and Slack FJ: Transcriptional control of microRNA expression in C.elegans: Promoting better understanding. RNA Biol 6: 49-53, 2009.

32. Kedde M, Strasser MJ, Boldajipour B, Oude Vrielink JA, Slanchev K, le Sage C, Nagel R, Voorhoeve PM, van Duijse J, Orom UA, et al: RNA-binding protein Dnd1 inhibits microRNA access to target mRNA. Cell 131: 1273-1286, 2007.

33. Krol J, Loedige I and Filipowicz W: The widespread regulation of microRNA biogenesis, function and decay. Nat Rev Genet 11: 597-610, 2010.

34. Qi Y and Li J: Triptolide inhibits the growth and migration of colon carcinoma cells by down-regulation of miR-191. Exp Mol Pathol 107: 23-31, 2019.

35. Wu CW, Wang SG, Lin ML and Chen SS: Downregulation of miR-144 by triptolide enhanced $p 85 \alpha-P T E N$ complex formation causing $\mathrm{S}$ phase arrest of human nasopharyngeal carcinoma cells. Eur J Pharmacol 855: 137-148, 2019.

36. Chen M, Wang JM, Wang D, Wu R and Hou HW: Triptolide inhibits migration and proliferation of fibroblasts from ileocolonic anastomosis of patients with Crohn's disease via regulating the miR161/HSP70 pathway. Mol Med Rep 19: 4841-4851, 2019.

37. Qian K, Zhang L and Shi K: Triptolide prevents osteoarthritis via inhibiting hsa-miR-20b. Inflammopharmacology 27: 109-119, 2019.

38. Xue M, Cheng Y, Han F, Chang Y, Yang Y, Li X, Chen L, $\mathrm{Lu}$ Y, Sun B and Chen L: Triptolide attenuates renal tubular epithelial-mesenchymal transition via the miR-188-5p-mediated PI3K/AKT pathway in diabetic kidney disease. Int J Biol Sci 14 1545-1557, 2018

39. Han F, Wang S, Chang Y, Li C, Yang J, Han Z, Chang B, Sun B and Chen L: Triptolide prevents extracellular matrix accumulation in experimental diabetic kidney disease by targeting microRNA-137/Notch1 pathway. J Cell Physiol 233: 2225-2237, 2018.

40. Cao Y, Guo Y, Wang Y, Cao Y, Zong R, Huang C and Liu J: Drug-containing serum of Xinfeng capsules protect against H9C2 from death by enhancing miRNA-21 and inhibiting toll-like receptor 4/phosphorylated p-38 (p-p38)/p-p65 signaling pathway and proinflammatory cytokines expression. J Tradit Chin Med 38: 359-365, 2018

41. Cao YX, Huang D, Liu J, Zong RK, Wan L, Huang CB, Zhang WD and Wang Y: A novel chinese medicine, xinfeng capsule, modulates proinflammatory cytokines via regulating the toll-like receptor 4 (TLR4)/Mitogen-activated protein kinase (MAPK)/Nuclear Kappa B (NF- $\mathrm{B}$ ) signaling pathway in an adjuvant arthritis rat model. Med Sci Monit 25: 6767-6774, 2019.

42. Xu X, Tian L and Zhang Z: Triptolide inhibits angiogenesis in microvascular endothelial cells through regulation of miR-92a. J Physiol Biochem 75: 573-583, 2019. 
43. Liang H, Zhang S and Li Z: Ginsenoside Rg3 protects mouse leydig cells against triptolide by downregulation of miR-26a. Drug Des Devel Ther 13: 2057-2066, 2019.

44. Mamoori A, Gopalan V and Lam AK: Role of miR-193a in cancer: Complexity and factors control the patterns of its expression. Curr Cancer Drug Targets 18: 618-628, 2018.

45. Svoronos AA, Engelman DM and Slack FJ: OncomiR or tumor suppressor? The duplicity of microRNAs in cancer. Cancer Res 76: 3666-3670, 2016.

46. Meng HT, Zhu L, Ni WM, You LS, Jin J and Qian WB: Triptolide inhibits the proliferation of cells from lymphocytic leukemic cell lines in association with downregulation of NF-kappaB activity and miR-16-1*. Acta Pharmacol Sin 32: 503-511, 2011.

47. Xiang W, Yang CY and Bai L: Mcl-1 inhibiton in cancer treatment. Onco Targets Ther 11: 7301-7314, 2018.

48. Chen Z, Sangwan V, Banerjee S, Mackenzie T, Dudeja V, Li X Wang H, Vickers SM and Saluja AK: miR-204 mediated loss of Myeloid cell leukemia-1 results in pancreatic cancer cell death Mol Cancer 12: 105, 2013.

49. Roufayel R and Kadry S: Molecular chaperone HSP70 and key regulators of apoptosis - a review. Curr Mol Med 19: 315-325, 2019.

50. MacKenzie TN, Mujumdar N, Banerjee S, Sangwan V, Sarver A, Vickers S, Subramanian S and Saluja AK: Triptolide induces the expression of miR-142-3p: A negative regulator of heat shock protein 70 and pancreatic cancer cell proliferation. Mol Cancer Ther 12: 1266-1275, 2013.

51. Hang S, Wang X and Li H: Triptolide inhibits viability and migration while promotes apoptosis in nephroblastoma cells by regulation of miR-193b-3p. Exp Mol Pathol 108: 80-88, 2019

52. Zhang H, Li H, Liu Z, Ge A, Guo E, Liu S and Chen Z: Triptolide inhibits the proliferation and migration of medulloblastoma Daoy cells by upregulation of microRNA-138. J Cell Biochem 119: 9866-9877, 2018.

53. Yao $\mathrm{C}, \mathrm{Li} \mathrm{H}$ and Zhang $\mathrm{W}$ : Triptolide inhibits benign prostatic epithelium viability and migration and induces apoptosis via upregulation of microR NA-218. Int J Immunopathol Pharmacol 32: 2058738418812349, 2018.

54. Liu Q, Wang W, Yang X, Zhao D, Li F and Wang H: miRNA-146a inhibits cell migration and invasion by targeting RhoA in breas cancer. Oncol Rep 36: 189-196, 2016.

55. Hu H, Tang J, Liu C and Cen Y: miR-23b promotes the migration of keratinocytes through downregulating TIMP3. J Surg Res 254: 102-109, 2020

56. Wang J, Zhou F, Yin L, Zhao L, Zhang Y and Wang J: MicroRNA-199b targets the regulation of ZEB1 expression to inhibit cell proliferation, migration and invasion in non-small cell lung cancer. Mol Med Rep 16: 5007-5014, 2017.

57. Charles S, Raj V, Arokiaraj J and Mala K: Caveolin1/protein arginine methyltransferase1/sirtuin 1 axis as a potential target against endothelial dysfunction. Pharmacol Res 119: 1-11, 2017.

58. Philips BJ, Kumar A, Burki S, Ryan JP, Noda K and D'Cunha J: Triptolide-induced apoptosis in non-small cell lung cancer via a novel miR204-5p/Caveolin-1/Akt-mediated pathway. Oncotarget 11: 2793-2806, 2020

59. Cao Y: Adipocyte and lipid metabolism in cancer drug resistance. J Clin Invest 129: 3006-3017, 2019.

60. Gomes BC, Rueff J and Rodrigues AS: MicroRNAs and cancer drug resistance. Methods Mol Biol 1395: 137-162, 2016.

61. Pfeffer SR, Yang CH and Preffer LM: The role of miR-21 in cancer. Drug Dev Res 76: 270-277, 2015.

62. Li X, Zang A, Jia Y, Zhang J, Fan W, Feng J, Duan M, Zhang L, Huo R, Jiao J and Zhu X: Triptolide reduces proliferation and enhances apoptosis of human non-small cell lung cancer cells through PTEN by targeting miR-21. Mol Med Rep 13: 2763-2768, 2016.

63. Li H, Hui L, Xu W, Shen H, Chen Q, Long L and Zhu X: Triptolide modulates the sensitivity of K562/A02 cells to adriamycin by regulating miR-21 expression. Pharm Biol 50: 1233-1240, 2012.

64. Wang R, Ma X, Su S and Liu Y: Triptolide antagonized the cisplatin resistance in human ovarian cancer cell line A2780/CP70 via hsa-mir-6751. Future Med Chem 10: 1947-1955, 2018

65. Huang X, Yang M and Jin J: Triptolide enhances the sensitivity of multiple myeloma cells to dexamethasone via microRNAs. Leuk Lymphoma 53: 1188-1195, 2012.

66. Jiang C, Fang X, Zhang H, Wang X, Li M, Jiang W, Tian F, Zhu L and Bian Z: Triptolide inhibits the growth of osteosarcoma by regulating microRNA-181a via targeting PTEN gene in vivo and vitro. Tumour Biol 39: 1010428317697556, 2017.
67. Jiang J, Song X, Yang J, Lei K, Ni Y, Zhou F and Sun L: Triptolide inhibits proliferation and migration of human neuroblastoma SH-SY5Y cells by upregulating MicroRNA-181a. Oncol Res 26: 1235-1243, 2018

68. O'Connell RM, Rao DS and Baltimore D: microRNA regulation of inflammatory responses. Annu Rev Immunol 30: 295-312, 2012.

69. Mahesh G and Biswas R: miRNA-155: A master regulator of inflammation. J Interferon Cytokine Res 39: 321-330, 2019.

70. Matta R, Wang X, Ge H, Ray W, Nelin LD and Liu Y: Triptolide induces anti-inflammatory cellular responses. Am J Transl Res 1: 267-282, 2009.

71. Tang H, Mao J, Ye X, Zhang F, Kerr WG, Zheng T and Zhu Z: SHIP-1, a target of miR-155, regulates endothelial cell responses in lung fibrosis. FASEB J 34: 2011-2023, 2020.

72. Wu R, Li Y, Guo Z, Gong J, Zhu W, Li N and Li J: Triptolide ameliorates ileocolonic anastomosis inflammation in IL-10 deficient mice by mechanism involving suppression of miR-155/SHIP-1 signaling pathway. Mol Immunol 56: 340-346, 2013.

73. Hou HW, Wang JM, Wang D, Wu R and Ji ZL: Triptolide exerts protective effects against fibrosis following ileocolonic anastomosis by mechanisms involving the miR-16-1/HSP70 pathway in IL-10-deficient mice. Int J Mol Med 40: 337-346, 2017.

74. Lee GR: The balance of Th17 versus Treg cells in autoimmunity. Int J Mol Sci 19: 730, 2018

75. Li XY, Wang SS, Han Z, Han F, Chang YP, Yang Y, Xue M, Sun B and Chen LM: Triptolide restores autophagy to alleviate diabetic renal fibrosis through the miR-141-3p/PTEN/Akt/mTOR pathway. Mol Ther Nucleic Acids 9: 48-56, 2017.

76. Jiang CB, Wei MG, Tu Y, Zhu H, Li CQ, Jing WM and Sun W: Triptolide attenuates podocyte injury by regulating expression of miRNA-344b-3p and miRNA-30b-3p in rats with adriamycin-induced nephropathy. Evid Based Complement Alternat Med 2015: 107814, 2015.

77. Ignarski M, Islam R and Muller RU: Long non-coding RNAs in kidney disease. Int J Mol Sci 20: 3276, 2019.

78. Bonauer A, Carmona G, Iwasaki M, Mione M, Koyanagi M, Fischer A, Burchfield J, Fox H, Doebele C, Ohtani K, et al: MicroRNA-92a controls angiogenesis and functional recovery of ischemic tissues in mice. Science 324: 1710-1713, 2009.

79. Zhang L, Zhou M, Qin G, Weintraub NL and Tang Y: miR-92a regulates viability and angiogenesis of endothelial cells under oxidative stress. Biochem Biophys Res Commun 446: 952-958, 2014.

80. Marrone AK, Beland FA and Pogribny IP: The role for microRNAs in drug toxicity and in safety assessment. Expert Opin Drug Metab Toxicol 11: 601-611, 2015.

81. Ichihara S, Li P, Mise N, Suzuki Y, Izuoka K, Nakajima T, Gonzalez F and Ichihara G: Ablation of aryl hydrocarbon receptor promotes angiotensin II-induced cardiac fibrosis through enhanced c-Jun/HIF-1 $\alpha$ signaling. Arch Toxicol 93: $1543-1553,2019$.

82. Nam HS, Hwang KS, Jeong YM, Ryu JI, Choi TY, Bae MA Son WC, You KH, Son HY and Kim CH: Expression of miRNA-122 induced by liver toxicants in Zebrafish. Biomed Res Int 2016: 1473578, 2016

83. Vliegenthart ADB, Wei C, Buckley C, Berends C, de Potter CMJ, Schneemann S, Del Pozo J, Tucker C, Mullins JJ, Webb DJ and Dear JW: Characterization of triptolide-induced hepatotoxicity by imaging and transcriptomics in a novel Zebrafish model. Toxicol Sci 159: 380-391, 2017.

84. Cheng B, Zhu Q, Lin W and Wang L: MicroRNA-122 inhibits epithelial-mesenchymal transition of hepatic stellate cells induced by the TGF- $\beta 1 /$ Smad signaling pathway. Exp Ther Med 17: 284-290, 2019.

85. Yuan Y, Tong L and Wu S: microRNA and NF-kappa B. Adv Exp Med Biol 887: 157-170, 2015.

86. Ichikawa D, Komatsu S, Konishi H and Otsuji E: Circulating microRNA in digestive tract cancers. Gastroenterology 142: 1074-1078 e1071, 2012.

87. Titov DV, Gilman B, He QL, Bhat S, Low WK, Dang Y, Smeaton M, Demain AL, Miller PS, Kugel JF, et al: XPB, a subunit of TFIIH, is a target of the natural product triptolide. Nat Chem Biol 7: 182-188, 2011

88. Chauhan AK, Li P, Sun Y, Wani G, Zhu Q and Wani AA: Spironolactone-induced XPB degradtion requires TFIIH integrity and ubiquitin-selective segregase VCP/p97. Cell Cycle 20: 81-95, 2021 
89. He QL, Titov DV, Li J, Tan M, Ye Z, Zhao Y, Romo D and Liu JO Covalent modification of a cysteine residue in the XPB subunit of the general transcription factor TFIIH through single epoxide cleavage of the transcription inhibitor triptolide. Angew Chem Int Ed Engl 54: 1859-1863, 2015.

90. Manzo SG, Zhou ZL, Wang YQ, Marinello J, He JX, Li YC, Ding J, Capranico G and Miao ZH: Natural product triptolide mediates cancer cell death by triggering CDK7-dependent degradation of RNA polymerase II. Cancer Res 72: 5363-5373, 2012.

91. Abascal-Palacios G, Ramsay EP, Beuron F, Morris E and Vannini A: Structural basis of RNA polymerase III transcription initiation. Nature 553: 301-306, 2018.

92. Liang X, Xie R, Su J, Ye B, Wei S, Liang Z, Bai R, Chen Z, Li Z and Gao X: Inhibition of RNA polymerase III transcription by Triptolide attenuates colorectal tumorigenesis. J Exp Clin Cancer Res 38: 217, 2019.

93. Yamagishi $M$ and Uchimaru K: Targeting EZH2 in cancer therapy. Curr Opin Oncol 29: 375-381, 2017.

94. Ihira K, Dong P, Xiong Y, Watari H, Konno Y, Hanley SJ, Noguchi M, Hirata N, Suizu F, Yamada T, et al: EZH2 inhibition suppresses endometrial cancer progression via miR-361/Twist axis. Oncotarget 8: 13509-13520, 2017.

95. Tamgue O, Chai CS, Hao L, Zambe JC, Huang WW, Zhang B, Lei $\mathrm{M}$ and Wei YM: Triptolide inhibits histone methyltransferase EZH2 and modulates the expression of its target genes in prostate cancer cells. Asian Pac J Cancer Prev 14: 5663-5669, 2013.
96. Akkoc Y and Gozuacik D: MicroRNAs as major regulators of the autophagy pathway. Biochim Biophys Acta Mol Cell Res 1867: Kappa B, 2020.

97. Gibbings D, Mostowy S, Jay F, Schwab Y, Cossart P and Voinnet O: Selective autophagy degrades DICER and AGO2 and regulates miRNA activity. Nat Cell Biol 14: 1314-1321, 2012.

98. Peng K, Li X, Wu C, Wang Y, Yu J, Zhang J, Gao Q, Zhang W, Zhang Q, Fan Y, et al: Derivation of haploid trophoblast stem cells via conversion in vitro. iScience 11: 508-518, 2019.

99. Wang H, Zhang W, Yu J, Wu C, Gao Q, Li X, Li Y, Zhang J, Tian Y, Tan T, et al: Genetic screening and multipotency in rhesus monkey haploid neural progenitor cells. Development 145: dev160531, 2018.

100. Huang Y, Zhu N, Chen T, Chen W, Kong J, Zheng W and Ruan J: Triptolide suppressed the microglia activation to improve spinal cord injury through miR-96/IKK $\beta / \mathrm{NF}-\kappa \mathrm{B}$ pathway. Spine (Phila Pa 1976) 44: E707-E714, 2019.

cC)(-) $($ This work is licensed under a Creative Commons Attribution-NonCommercial-NoDerivatives 4.0 International (CC BY-NC-ND 4.0) License. 